\title{
Expandable Micro-motor Bur, design of a new device for least invasive extraction of broken teeth roots
}

\author{
Amir Hashem Shahidi Bonjar
}

\begin{abstract}
Background: Extraction of a broken tooth root is often a traumatic experience for both the practitioner and the patient. To extract broken roots, generally invasive approaches as open window surgeries or mucoperiosteal flap and/or removal of buccal bone are performed.

Presentation of the hypothesis: Expandable micro-motor bur (EMB) is a hypothetical design of a dental instrument proposed for removal of broken teeth roots that cannot be extracted by the routine closed methods and in which common instrumentations cannot afford to accomplish. Implication of EMB would introduce a new technique in removal of broken teeth roots in which surgical trauma is minimized and so post-extraction disorders. It would eliminate surgical invasion to the surrounding tissues; and also it would eliminate profound hand forces by the practitioner, consequently reduces stress for both the practitioner and the patient. It would eliminate high risk aftermaths such as operative morbidity (due to bone loss), maxillary sinus exposure and probable need for additional surgery as are indicative of some conventional open access approaches.
\end{abstract}

Testing the hypothesis: Further studies are needed to confirm its effect in clinical cases. The effectiveness of EMB should be verified firstly by animal experiments. The likelihood of its negative influence on nearby vascular and nerve system should be well evaluated.

Implications of the hypothesis: Implication of EMB would be of interest to both patients and the surgeon due to the following main achievements: a) no need for mucoperiosteal flap, hence preservation of soft tissue, b) no need for osteotomy, hence retention of buccal bone, c) less risk of sinus exposure, d) minimum chance of post operative infections due to eliminated surgeries in soft tissues and bones and e) in terms of esthetics, it will have a special meaning for immediate placement of dental implants. EMB's structural components include Bur head, Spacers and Bur base. A micro motor would power its spin. In contrast to conventional surgical approaches, EMB procedure is conservative. It is anticipated that EMB would provide less traumatic and least post-operative complications in extraction of broken teeth roots.

Keywords: Tooth extraction, Complicated root extraction, Expandable micro-motor bur, EMB

\section{Background}

The broken teeth roots may be difficult to remove and the dentist should strongly consider performing an open extraction after initial attempts at forceps removal have failed [1-3]. Open extractions include invasive open window surgeries or mucoperiosteal flap and/or removal of buccal bone [4-10]. Occasionally, it

\footnotetext{
Correspondence: shahidiah@gmail.com

Students Research Committee, Dental School, Shahid Beheshti University of Medical Sciences, Tehran, 1983963113, Iran
}

is necessary to prepare a purchase point with the bur and to use an elevator as the Crane pick to elevate the remaining root $[11,12]$. However, these treatments have aftermaths characterized by post-operative disorders [13-17]. Therefore, seeking an easy and effective method to remove broken teeth roots and resolve the operative and post operative complications is necessary for dental clinicians and the patients.

\section{Biomed Central}

(C) 2013 Shahidi Bonjar; licensee BioMed Central Ltd. This is an Open Access article distributed under the terms of the Creative Commons Attribution License (http://creativecommons.org/licenses/by/2.0), which permits unrestricted use, distribution, and reproduction in any medium, provided the original work is properly cited. 


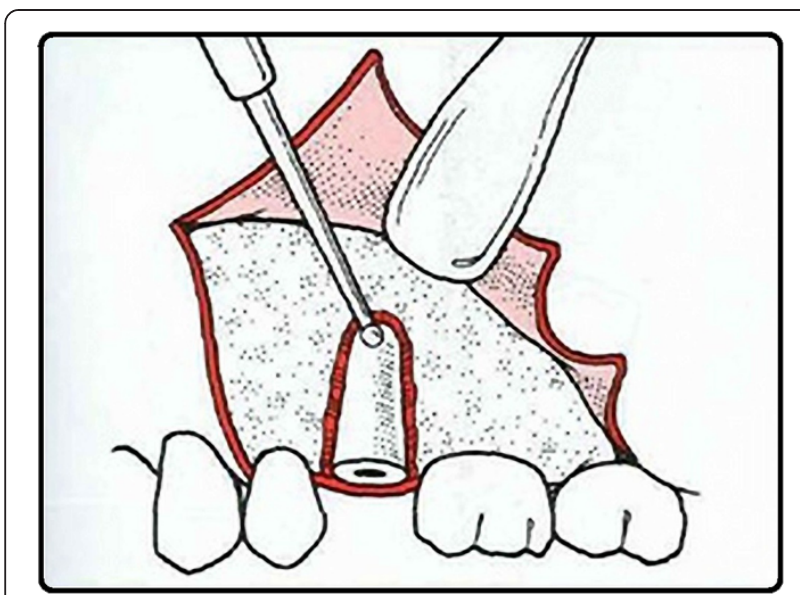

Figure 1 A conventional open root extraction surgery [1]. The sketch shows soft tissue flap and removal of buccal bone for insertion of elevator to elevate the root from its socket. This invasive approach may cause more operative morbidity due to bone loss and probable need for additional surgery.

General information on extractions of broken teeth roots Retrieving broken teeth roots is generally accompanied with invasive techniques as mucoperiosteal flaps and removal of buccal bone (Figure 1) or open-window approach (Figure 2) [1]. Consequently, such invasive surgeries are accompanied with post-operative maladies as

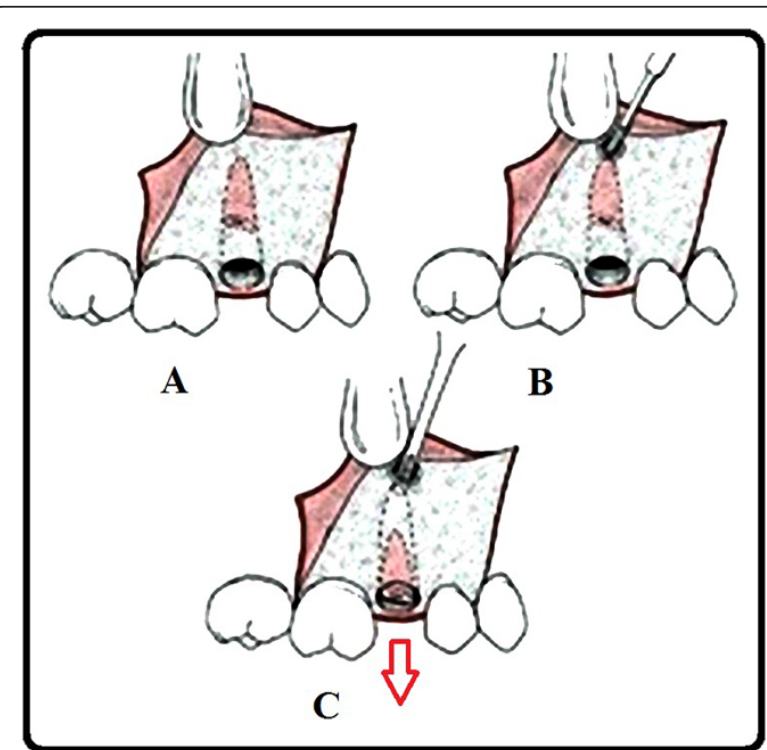

Figure 2 Open-window approach for root is indicated when buccocrestal bone must be maintained. A) three-cornered flap is reflected to expose area overlying apex of root fragment being recovered, B) bur is used to uncover apex of root and allow sufficient access for insertion of straight elevator and $\mathbf{C}$ ) small straight elevator is then used to displace root out of its socket [1]. pain, swelling, trismus, infection, prolonged bleeding, sinus exposure, nerve injury and innervations disorders $[13-16,18]$. However, the extent of such maladies depend on a number of factors such as the duration of the operation, difficulty of the surgery, the magnitude of the osteotomy/mucoperiosteal flap $[7,8]$, the lack of oral hygiene and the experience of the surgeon [6,19-25].

\section{Hypothesis}

As a non-invasive treatment, EMB has not ever been reported to be utilized in dental surgery. The hypothesis I propose here is that EMB may be an adjunct treatment for extractions of broken teeth roots. This hypothesis is based on the following points: (1) No need for mucoperiosteal flap, hence preservation of soft tissue, (2) no need for osteotomy, hence retention of buccal bone, (3) reduced invasion to surrounding anatomical structures and less risk of sinus exposure, hence control of operative and post-operative complications.

\section{Proposed parts of EMB}

As indicated in Figure 3, structural components of EMB include: 1) Bur Head which consists of Split round bur and Hallow grooved shaft and 2) Bur base which consists of Spiral grooved shaft, Spacers and Main shank. A micro motor would power its spin.

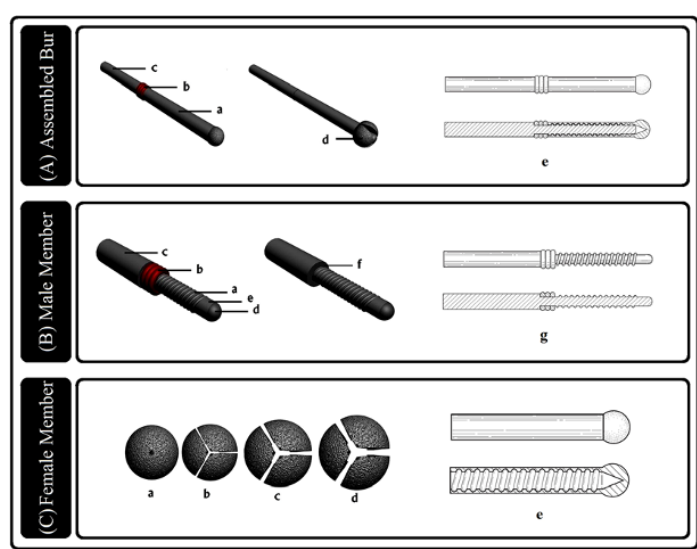

Figure 3 Structural components of Expandable Micro-motor Bur. A) Bur components in position, Bur Head (female member) (a), Spacers (b), Bur Base (male member) (c) clutched together for mounting to micro-motor through Main shank, expanded Bur Head (d) and cross-section view (e). B) Bur Base (male member) consists of Spiral grooved shaft (a), Spacers (b) and Main shank (c); the tip portion is round (d) and grooveless (e), spacers removed from male member ( $f$ ) and cross-section view (g). C) Bur Head (female member), tip view of Bur Head spinning in root canal. Different degrees of expansion occurs in the canal as shown while Spiral grooved shaft bears three (a), two (b), one (c), no spacers (d) and cross-section view (e). 


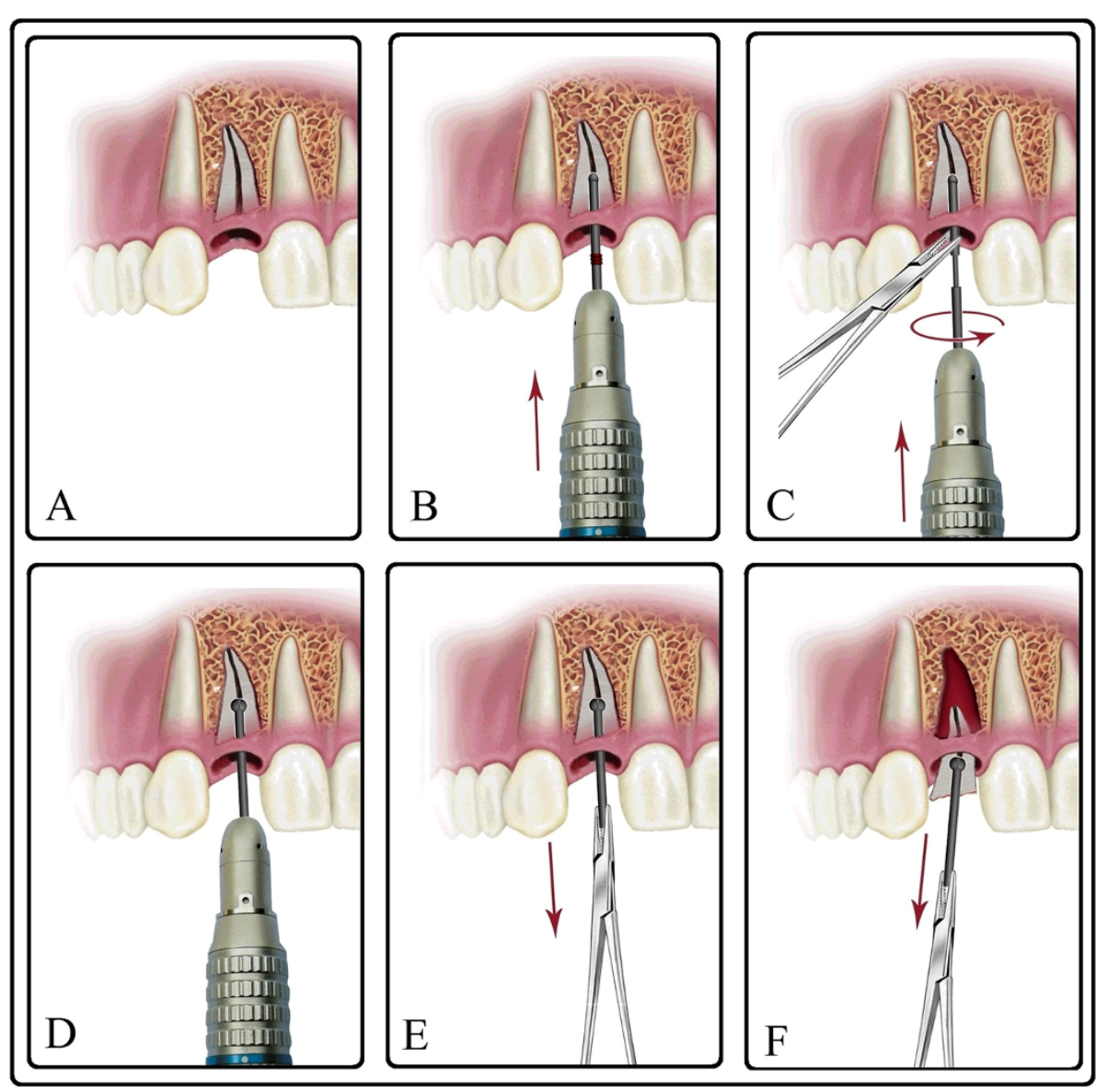

Figure 4 Proposed procedure in which Expandable Micro-motor Bur removes broken root from its socket. A) Broken root in its socket. B) By using micro-motor, Round bur drilled about half way through root canal similar to a conventional bur. Note that spacers are on. C) Spin stops, EMB removed from canal, micro motor detached from EMB, Round bur unscrewed from Bur base, Spacers reduced or totally removed, Round bur placed back into canal, Bur base mounted on micro-motor, by help of a needle holder Round bur and Bur base screwed back. Expanding Round bur carves its periphery making a spherical cavity around itself. This step is run for a very short period. D) Spin stops, Micro-motor detached and EMB remains in place. While expanded in root canal, Split round bur behaves as an efficient extraction aiding anchor. E, F) The firm anchor eases extraction of the broken root with the help of a needle holder.

Table 1 Comparison between "conventional extraction of complicated roots "and "Expandable Micro-motor Bur technique"

\begin{tabular}{lll}
\hline Criteria & $\begin{array}{l}\text { Conventional complicated root- } \\
\text { extraction }\end{array}$ & $\begin{array}{l}\text { Expandable Micro- } \\
\text { motor Bur }\end{array}$ \\
\hline $\begin{array}{l}\text { Invasion to surrounding anatomical structures (maxillary sinus exposure, nerve injury } \\
\text { and innervations disorders) } \\
\text { Need for mucoperiosteal flap and/or osteotomy of buccal bone }\end{array}$ & More probable & Less probable \\
Surgical approach & More probable & $\begin{array}{l}\text { No or with less } \\
\text { extension }\end{array}$ \\
Operative and post-operative complications & More invasive & More conservative \\
Operation duration & More probable & Less probable \\
Stress of practitioner and patient & Longer & Shorter \\
Success of immediate implant placement & More & Less \\
\hline
\end{tabular}




\section{Clinical implication}

EMB is proposed to remove broken teeth roots in a conservative manner. It bears less stress for both patient and practitioner. Details of the implementation of EMB to remove a broken tooth root are schematically presented stepwise in Figure 4. The following points support EMB's applicability for clinical use: 1) with expansion in root canal it behaves as an efficient extraction aiding anchor (as a false tooth crown), 2) since expansion and carving occur simultaneously in cavity (unlike expansion of a screw anchor in a wall hole), cracking in root walls is prevented, 3 ) there is low chance for breakage of the root walls since the carved cavity made by EMB is spherical and formation of sharp edges is prevented, hence the force applied for extraction will be evenly distributed in the root, 4) it is suitable for all sizes of roots since the expansion rate of the Split round bur is adjusted with application of suitable bur sizes and also use of proper number of spacers. Accordingly, for smaller root, there would be need for smaller bur size and less reduction in spacer numbers (causing minute expansion), 5) Bur Head is disposable single use, hence low chance of infection, 6) minimum post-extraction disorders, 7) shortened rehabilitation period, and 8) freshly evacuated root sockets are useful in dental implants for restoration in patients with tooth loss upon which a higher survival rate of the implants will ensue $[3,17]$. Comparison between conventional complicated root-extraction with $\mathrm{EMB}$ procedures is presented in Table 1.

\section{Future testing}

Considering the application of this treatment, further studies are needed to confirm its effect in clinical cases. The effectiveness of EMB should be verified firstly by animal experiments. The likelihood of its negative influence on nearby vascular and nerve system should be well evaluated. When these concerns are clear, I believe that EMB could be used as a new tool to assist removal of broken teeth roots in humans.

\section{Competing interest}

The author declares that he has no competing interests with others. I also declare that I have no financial and personal relationships with other people or organizations that can inappropriately influence my work, there is no professional or other personal interest of any nature or kind in any product, service and/or company that could be construed as influencing the position presented in, the article entitled, "Expandable micro-motor bur, design of a new device for least invasive extraction of broken teeth roots".

\section{Authors' contributions}

AHSB carried out the entire design of the study and draft the manuscript. He read and approved the final manuscript.

\section{Acknowledgement}

I like to express my deepest thanks for help, scientific advice and support to: Professor M. Yaghmaei, Oral and Maxillofacial Surgeon and Head of the Oral and Maxillofacial Surgery Department; Dr A. Khojasteh, Oral and Maxillofacial
Surgeon and Head of Exceptional Talent Center of the College of Dentistry; Dr M. Nouri, Orthodontist and Head of Communication and Information Technology Center; Dr F. Poordanesh, Oral and Maxillofacial Surgeon; Dr M. Ghasemianpour, Orthodontist; Dental School, Shahid Beheshti University of Medical Sciences of Iran

Received: 13 March 2012 Accepted: 13 November 2012

Published: 5 March 2013

\section{References}

1. Peterson LJ: Principles of complicated exodontia. In Contemporary principles of oral and maxillofacial surgery. 4th edition. Edited by Peterson E, Ellis E, Hupp JR, Tucker MR: St. Louis, Mosby Inc:; 2004, 156-183.

2. Nageshwar RD: Common incision for impacted mandibular third molars J Oral Maxillofac Surg 2002, 60:1506-1509.

3. Chin Quee TA, Gosselin D, Millar EP, Stamm JW: Surgical removal of the fully impacted mandibular third molar. The influence of flap design and alveolar bone height on the periodontal status of the second molar. J Periodontol 1985, 10:625-631.

4. Sutherland KJG: Mucoperiosteal flaps in dento-alveolar surgery. Aust Dent J 1963, 6:317-325.

5. Capuzzi P, Montebugnoli L, Vaccaro MA: Extraction of impacted third molars. A longitudinal prospective study on factors that affect postoperative recovery. Oral Surg Oral Med Oral Pathol 1994, 77:314-323.

6. Garcia Garcia A, Gude Sampedro F, Gandara Rey J, Gallas Torreria M: Trismus and pain after removal of impacted lower third molars. J Oral Maxillofac Surg 1997, 55:1223-1226.

7. Stephen RJ, App GR, Foreman DW: Periodontal evaluation of two mucoperiosteal flaps used in removing impacted mandibular third molars. J Oral Maxillofac Surg 1983, 41:719-725.

8. Groves BJ, Moore JR: The periodontal implications of flap design in lower third molar extractions. Dent Pract Dent Rec 1970, 20:297-304.

9. Rosa AL, Carneiro MG, Lavrador MA, Novaes AB: Influence of flap design on periodontal healing of second molars after extraction of impacted mandibular third molars. Oral Surg Oral Med Oral Pathol Oral Radiol Endod 2002, 93:404-409.

10. Suarez-Cunqueiro MM, Gutwald R, Reichman J, Otero-Cepeda XL, Schmelzeisen R: Marginal flap versus paramarginal flap in impacted third molar surgery: A prospective study. Oral Surg Oral Med Oral Pathol Oral Radiol Endod 2010, 95:403-408.

11. Dostalova T, Seydlova M: Dentistry and Oral Diseases for Medical Students. Havlickuv Brod, Czech Republic: Grada Publishing; 2010:74.

12. Van der Weijden F, Dell Acqua F, Else Slot D: Alveolar bone dimensional changes of post-extraction sockets in humans: a systematic review. J Clin Periodontol 2009, 36:1048-1058.

13. Jakse N, Bankaoglu V, Wimmer G, Eskici A, Petl C: Primary wound healing after lower third molar surgery: Evaluation of two different flap designs. Oral Surg Oral Med Oral Pathol Oral Radiol Endod 2002, 93:7-14.

14. Clauser $C$, Barone R: Effect of incision and flap reflection on postoperative pain after the removal of partially impacted mandibular third molars. Quintessence Int 1994, 25:845-849.

15. Garcia Garcia A, Gude Sampedro F, Gallas Torrella M, Gandara Vila P, MadrinanGrana P, Gandara-Rey JM: Trismus and pain after removal of a lower third molar. Effects of raising a mucoperiosteal flap. Med Oral 2001, 6:391-396.

16. Penarrocha M, Sanchis JM, Saez U, Gay C, Bagan VJ: Oral hygiene and postoperative pain after mandibular third molar surgery. Oral Surg Oral Med Oral Pathol Oral Radiol Endod 2001, 92:260-264.

17. Retzepi M, Donos N: Guided Bone Regeneration: biological principle and therapeutic applications. Clin Oral Implants Res 2010, 21:567-572.

18. Stephens JR, App GR, Foreman DW: Periodontal evaluation of two mucoperiosteal flaps used in removing impacted mandibular third molars. J Oral Maxillofac Surg 1983, 41:719-725.

19. Charles AK, Ramfjord SP: Healing of gingival mucoperiosteal flaps. Oral Surg Oral Med Oral Pathol 1960, 13:89-103.

20. Wadhwani KK, Garg A: Healing of soft tissue after different types of flap designs used in periapical surgery. Endodontology 2004, 16:20-22.

21. Monaco G, Daprile G, Tavernese L, Corinaldesi G, Marchetti C: Mandibular third molar removal in young patients: an evaluation of 2 flap designs. J Oral Maxillofac Surg 2009, 67:16-21.

22. Sanchis Bielsa JM, Bazan SH, Penarrocha Diego M: Flap repositioning versus conventional suturing in third molar surgery. Med Oral Patol Oral Cir Bucal 2008, 13:138-142 
23. Schofield IDF, Kogon SL, Donner A: Long-term comparison of two surgical flap designs. J Can Dent Assoc 1988, 54:689-695.

24. Barone A, Aldini NN, Fini M, Giardino R, Calvo Guirado JL, Covani U: Xenograft versus extraction alone for ridge preservation after tooth removal: a clinical and histomorphomeric study. J Periodontol 2008, 79:1370-1377.

25. Quee TA, Gosselin D, Millar EP, Stamm JW: Surgical removal of the fully impacted mandibular third molar. The influence of flap design and alveolar bone height on the periodontal status of the second molar. J Periodontol 1985, 56:625-630.

doi:10.1186/1750-1164-7-2

Cite this article as: Shahidi Bonjar: Expandable Micro-motor Bur, design of a new device for least invasive extraction of broken teeth roots. Annals of Surgical Innovation and Research 2013 7:2.

\section{Submit your next manuscript to BioMed Central and take full advantage of:}

- Convenient online submission

- Thorough peer review

- No space constraints or color figure charges

- Immediate publication on acceptance

- Inclusion in PubMed, CAS, Scopus and Google Scholar

- Research which is freely available for redistribution 